\title{
Ageing with Chagas disease: an overview of an urban Brazilian cohort in Rio de Janeiro
}

Alexandre Gomes Vizzoni, Margareth Catoia Varela, Luiz Henrique Conde Sangenis, Alejandro Marcel Hasslocher-Moreno, Pedro Emmanuel Alvarenga Americano do Brasil and Roberto Magalhães Saraiva* (1)

\begin{abstract}
Background: Chagas disease control programmes have decreased the prevalence of Chagas disease in Latin America. Together with migration to urban areas and increase in life expectancy, a new scenario for Chagas disease has emerged in Brazil with most patients currently elderly individuals living in urban areas. However, acute Chagas disease cases still occur due to vector transmission by sylvatic vectors and oral transmission by contaminated food. Therefore, we characterized the clinical and epidemiological profile of the patients followed at Evandro Chagas National Institute of Infectious Diseases in Rio de Janeiro, Brazil. We aimed to identify the clinical forms, associated co-morbidities, and geographical areas where younger patients originate from. This will aid in the identification of potential challenges to be currently faced.
\end{abstract}

Results: This is a cross-sectional study. Adult patients with chronic Chagas disease were recruited between March 2013 and April 2016. Clinical and epidemiological data were obtained from electronic medical records and interviews. The clinical form of the Chagas disease presented by the patients was determined following the Brazilian Consensus on Chagas disease. Six hundred and nineteen patients (mean age $60 \pm 12$ years; 56.9\% women) were included in this study. Patients' clinical forms were classified as follows: indeterminate 29.1\%; cardiac 55.4\%; digestive 5.5\%; and mixed 10.0\%. Patients aged over 65 years comprised 38\% of the population. Hypertension was present in 347 (56\%) patients, dyslipidemia in 261 patients (42\%) and diabetes mellitus in 185 patients (30\%). There were no differences regarding gender, race, comorbidities frequency or place of origin across Chagas disease clinical forms. Most of the elderly population originated from Bahia, Minas Gerais and Pernambuco states, while most of the younger patients were born in Ceará, Paraíba and Rio de Janeiro states.

Conclusions: We described a great proportion of elderly patients in the composition of an urban Brazilian Chagas disease patient cohort with a high prevalence of comorbidities. We also identified a change in the pattern of the place of origin among younger patients.

Keywords: Chagas disease, Elderly patients, Neglected tropical disease, Trypanosoma cruzi, Geoprocessing

\footnotetext{
* Correspondence: roberto.saraiva@ini.fiocruz.br

Evandro Chagas National Institute of Infectious Diseases, Oswaldo Cruz

Foundation, Rio de Janeiro, Brazil
}

(c) The Author(s). 2018 Open Access This article is distributed under the terms of the Creative Commons Attribution 4.0 International License (http://creativecommons.org/licenses/by/4.0/), which permits unrestricted use, distribution, and reproduction in any medium, provided you give appropriate credit to the original author(s) and the source, provide a link to the Creative Commons license, and indicate if changes were made. The Creative Commons Public Domain Dedication waiver (http://creativecommons.org/publicdomain/zero/1.0/) applies to the data made available in this article, unless otherwise stated. 


\section{Background}

Chagas disease (CD) or American trypanosomiasis is a potentially life-threatening illness caused by the parasite Trypanosoma cruzi. An estimated 5-6 million people live with CD in Latin American countries [1] and CD is responsible for approximately 12,000 deaths per year [2]. However, $\mathrm{CD}$ has been increasingly detected in the last decades in USA, Canada, many European and some Western Pacific countries as a result of migration from Latin America to the rest of the world [3, 4]. In Brazil, 1.1-4.6 million are estimated to live with chronic $\operatorname{CD}[1,5,6]$. Between 2000 and 2011, CD was still the main cause of death due to neglected tropical diseases in Brazil with an average annual age-adjusted mortality of 3.4 deaths per 100,000 populations [7]. The economic burden is also high in Brazil which has the highest annual health-care costs in Latin America (mean \$129,211,209) [8].

Chagas disease was largely confined to rural areas where wild triatomines adapted to human dwellings by creating domestic colonies in mud walls and roofs. However, the urbanization of Latin American countries led to an intense migration from rural to urban areas during the 20th century where the disease could still be transmitted by blood transfusion [9]. In Brazil, until the 1950s, CD was recognized as a rural endemic disease in a context of high social vulnerability and the main mode of transmission was vector-borne [6]. However, in the second half of the 20th century the Brazilian industrialization resulted in a great urbanization process with massive migration movements. In this period alone, the Brazilian urban population increased from 19 to 138 million inhabitants, growing on a 7.3-fold basis. Most of the urban demographic growth, between 1960 and 1980, was due to the intense rural-urban migratory flow with nearly 43 million people leaving the countryside toward the cities [10]. Therefore, CD posed an increasing health and economic burden to Latin American countries which was lastly recognized in the 1970s when extensive and coordinated control programmes started in Latin American countries, such as Brazil. In Brazil, 18 states were included in $\mathrm{CD}$ endemic areas with risk of disease transmission by the main vector $T$. infestans [11]. Systematic control measures led to a great decrease in houses domiciled by this vector and a simultaneous reduction in the transmission of $T$. cruzi to humans $[5,12]$. Besides the control of triatomines domestic colonies, blood donor screening for $\mathrm{CD}$ also contributed to a dramatic decrease in the number of new CD cases. In 2006, Brazil received an international certification issued by the Pan American Health Organization (PAHO) and the World Health Organization for the interruption of CD transmission by blood transfusion and T. infestans [13].

Although the incidence of new CD cases has decreased, the number of individuals already infected with T. cruzi is still an issue of primary concern, as CD is a lifelong infection with a variable degree of morbidity. Almost one third of the T. cruzi-infected subjects will eventually develop chronic Chagas heart disease [6]. On the other hand, acute CD cases still occur linked to vector transmission by native vectors, which can occasionally invade domiciles. Acute cases may also occur through oral transmission, which is associated with food contaminated by infected vectors mainly in Amazon region [14].

The main consequence of $C D$ control programmes over time is that most CD patients currently under health care are much older individuals when compared to subjects under health care in the 1990s $[15,16]$. Together with the ageing of $C D$ patients, the urbanization process of the Brazilian society has increased the probability of chronic-degenerative comorbidities occurring in patients with chronic CD [6]. Therefore, the aim of this study was to characterize the clinical and epidemiological profile of CD patients followed at the outpatient service of the Evandro Chagas National Institute of Infectious Disease (INI) located in the State of Rio de Janeiro, Brazil. This will aid in the identification of potential challenges to be faced to provide adequate healthcare to this elderly CD population and at the same time we will identify the epidemiological profile of young CD patients in order to identify the geographical areas from where they are originated.

\section{Methods \\ Study design}

This is a cross-sectional study conducted at INI from March 2013 to April 2016. Patients were recruited from patients attending the institutional outpatient service. The INI is a national reference center for treatment and research in infectious diseases and tropical medicine. All patients were previously diagnosed with 2 simultaneously positive CD serological tests (enzyme-linked immunosorbent assay and indirect immunofluorescence) [17].

The following data were obtained from electronic medical records filed at INI: gender, age, place of origin, comorbidities and symptoms related to $\mathrm{CD}, \mathrm{CD}$ classification and left ventricular ejection fraction (LVEF). We considered the limit of 65 years-old in classifying patients as elderly, according to the World Health Organization [18].

The CD classification followed the Brazilian Consensus on Chagas disease: indeterminate form, cardiac form (stage A, B1, B2, C and D), digestive form (megaesophagus and megacolon) and mixed form (cardio digestive) [6].

\section{Geoprocessing methodology}

The spatial analysis of health data was done in QGIS software version 2.12.2, using the map of the Brazilian municipal mesh of 2013. The naturalness of each patient was coded according to the Brazilian Institute of Geography and Statistics Municipality Codes table, which allowed the georeferencing in the maps used. We summed the number 
of cases per municipality and generated the maps of the dataset with the whole population, and stratified by age group.

\section{Statistical analysis}

All statistical analyses were performed using SPSS version 21 (SPSS, Chicago, USA). All continuous values passed the Kolmogorov-Smirnov test of normality. Normally distributed data were described as mean \pm standard deviation and compared by one-way analysis of variance (ANOVA) with Bonferroni correction. Categorical variables were described as absolute and percentage values and compared by means of contingency tables. A $P$-value of $<0.05$ was considered statistically significant.

\section{Results}

Patients' characteristics

From a total of 932 patients enrolled in our outpatient service during the period of the study, 670 (71.9\%) were recruited and 619 patients $(66.4 \%)$ agreed to participate in this study. There were a slightly higher number of women than men (56.9\%). Women were slightly older than men $(61.0 \pm 11.9$ years $v s 59.0 \pm 12.4$ years, $t=-2.05, P=0.04)$. Regarding CD classification, 180 patients (29.1\%) presented the indeterminate form, $343(55.4 \%)$ presented the cardiac form, $34(5.5 \%)$ the digestive form and $72(10.0 \%)$ the mixed (cardio plus digestive) form. Patients with the cardiac form were further classified into stages: 116 (33.8\%) belonged to stage A, 111 (32.4\%) to stage B1, 19 (5.5\%) to stage B2, 79 (23.0\%) to stage C and 18 (5.3\%) to stage D. Among patients with the digestive form, 29 (85.3\%) presented megaesophagus and 5 patients (14.7\%) presented megacolon. Among patients with the mixed form, most of them also presented megaesophagus (85.5\%), while megacolon was present in $14.5 \%$ of the patients.

A total of 236 (38.1\%) patients aged over 65 years-old, 309 (49.9\%) aged between 45 and 64 years-old, and 74 $(12.0 \%)$ aged under 45 years-old. There were no significant differences in gender or race distribution among the different CD clinical forms (Table 1). Regarding age, patients with the indeterminate form were younger than patients with the cardiac, digestive, or mixed forms (Table 1).

All data used for this study are described in detail in a supplemental dataset (Additional file 1: Table S1).

\section{Time living outside endemic area}

The time living outside the endemic area was less than 10 years for 51 patients (8.5\%), between 10 to 20 years for 153 patients (25.5\%), and more than 20 years for 379 patients (63.3\%). Additionally, 16 patients (2.7\%) were born in the State of Rio de Janeiro and never lived in an endemic area. Therefore, most patients followed at our institution moved from rural to urban areas decades ago. There was a preponderance of people who moved away from endemic

Table 1 Distribution of socio-demographic characteristics in the studied groups

\begin{tabular}{|c|c|c|c|c|c|c|}
\hline \multirow[t]{2}{*}{ Variable } & \multicolumn{6}{|c|}{ Clinical form $n(\%)(n=619)$} \\
\hline & Indeterminate $(n=180)$ & Cardiac $(n=343)$ & Digestive $(n=34)$ & Mixed $(n=62)$ & Total $(n=619)$ & $P$-value \\
\hline \multicolumn{6}{|l|}{ Sex } & 0.194 \\
\hline Male & $76(42.2)$ & $156(45.5)$ & $9(26.5)$ & $26(41.9)$ & $267(43.1)$ & \multirow[t]{2}{*}{-} \\
\hline Female & $104(57.8)$ & $187(54.5)$ & $25(73.5)$ & $36(58.1)$ & $352(56.9)$ & \\
\hline Age, years & $55.5 \pm 12.7$ & $61.5 \pm 11.3$ & $61.6 \pm 13.9$ & $65.2 \pm 9.6$ & $60.1 \pm 12.1$ & $<0.001$ \\
\hline \multicolumn{6}{|l|}{ Ethnicity } & 0.926 \\
\hline Caucasian & $73(40.5)$ & $142(41.4)$ & $16(47.1)$ & $23(36.5)$ & $254(41.0)$ & \multirow[t]{3}{*}{-} \\
\hline Afro-Brazilian & $25(13.9)$ & $46(13.4)$ & $6(17.6)$ & $10(15.9)$ & $87(14.1)$ & \\
\hline Mixed/Pardo & $82(45.6)$ & $155(45.2)$ & $12(35.3)$ & $29(46.8)$ & $278(44.9)$ & \\
\hline \multicolumn{6}{|l|}{ Place of origin } & 0.192 \\
\hline North & - & $1(0.3)$ & - & - & $1(0.2)$ & \multirow[t]{5}{*}{-} \\
\hline Northeast & $118(65.6)$ & $243(70.8)$ & $24(70.6)$ & $40(64.6)$ & 425 (68.6) & \\
\hline South & $8(4.4)$ & $1(0.3)$ & - & $2(3.2)$ & $11(1.8)$ & \\
\hline Southeast & $52(28.9)$ & $91(26.6)$ & $10(29.4)$ & 19 (30.6) & $172(27.8)$ & \\
\hline Central-West & $2(1.1)$ & $7(2.0)$ & - & $1(1.6)$ & $10(1.6)$ & \\
\hline \multicolumn{7}{|c|}{ Time outside the endemic area } \\
\hline$<10$ years & $24(13.8)$ & $25(7.5)$ & $2(6.1)$ & - & $51(8.5)$ & 0.002 \\
\hline 10-20 years & $53(30.5)$ & $73(22.0)$ & $6(18.2)$ & $21(35)$ & $153(25.5)$ & \multirow[t]{3}{*}{-} \\
\hline$>20$ years & $90(51.7)$ & $227(68.4)$ & $25(75.7)$ & $37(61.7)$ & $379(63.3)$ & \\
\hline Born in RJ state & $7(4.0)$ & $7(2.1)$ & - & $2(3.3)$ & $16(2.7)$ & \\
\hline
\end{tabular}


areas a longer time ago among patients with the cardiac $\left(\chi^{2}=4.479, d f=3, P=0.001\right)$ and mixed forms $\left(\chi^{2}=9.434, d f=3, P=0.009\right)$ than in patients with the indeterminate form.

\section{Place of birth}

Regarding place of origin, most patients were born in the Northeast $(425,68.6 \%)$ and Southeast $(172,27.8 \%)$ Brazilian regions. The number of patients from other Brazilian regions was lower: North (1, 0.2\%), Central-West (10, 1.6\%) and South (11, 1.8\%) regions. The proportion of patients with the different CD forms was similar among Brazilian regions (Table 1, Fig. 1).

Most patients came from rural areas. For instance, all patients from Minas Gerais State and 134 patients (89.3\%) from the State of Bahia were born in rural areas. Among older individuals, most patients were born in Bahia, Minas Gerais and Pernambuco states. The municipalities most often cited by the patients as their places of origin were: Mairi (10, 6.6\%), Cachoeira (7, 4.7\%) and Feira de Santana (5, 3.3\%) located in the State of Bahia, Araçuaí (11, 8.45\%), Montes Claros (9, 6.9\%) and Engenheiro Navarro (6, 4.6\%) located in the State of Minas Gerais, and Timbaúba de Mocós $(4,6.5 \%)$ located in the State of Pernambuco. On the other hand, the majority of the younger individuals were born in Ceará, Paraíba e Rio de Janeiro states $\left(\chi^{2}=137.97, d f=34, P<0.001\right)$. Among those, the most frequently cited municipalities were Nova Russas in the State of Ceará $(n=8)$, Desterro in the State of Paraíba $(n=7)$ and Rio de Janeiro in the State of Rio de Janeiro ( $n=6$; Table 2, Fig. 2).

\section{Infection route}

The route of transmission was vector-borne in 542 (90.5\%) of the patients, blood transfusion in 10 patients (1.7\%), vector-borne or blood transfusion in 23 patients (3.8\%) and vertical in 24 patients $(4.0 \%)$.

\section{Comorbidities and left ventricular ejection fraction}

Hypertension was present in 347 patients (56.1\%), dyslipidemia in 261 patients (42.2\%), and type 2 diabetes mellitus in 185 patients (29.9\%). Consequently, at least one comorbidity was present in $71.9 \%$ of the patients. Comorbidities frequency per clinical form was similar

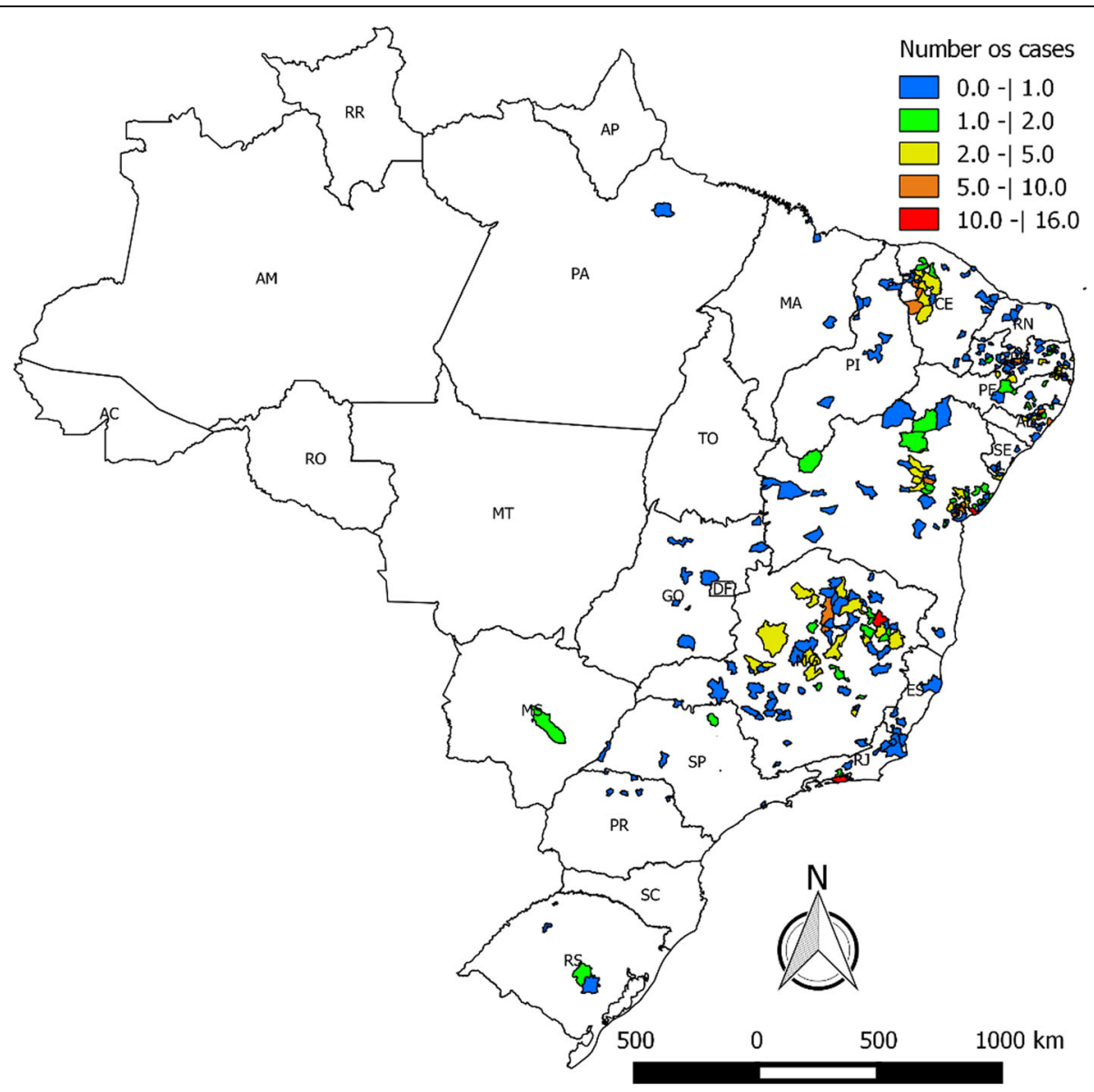

Fig. 1 Place of origin of the patients with Chagas disease who constitute the INI cohort 
Table 2 Distribution of patient frequencies by age group in the different states

\begin{tabular}{lllll}
\hline State & \multicolumn{4}{l}{ Age group n (\%) } \\
\cline { 2 - 5 } & $18-44$ years & $45-64$ years & $\geq 65$ years & Total \\
\hline Alagoas & $5(6.8)$ & $28(9.1)$ & $15(6.3)$ & $48(7.8)$ \\
Bahia & $7(9.5)$ & $72(23.3)$ & $71(30.1)$ & $150(24.2)$ \\
Ceará & $27(36.5)$ & $31(10.0)$ & $8(3.9)$ & $66(10.7)$ \\
Espírito Santo & $2(2.7)$ & $1(0.3)$ & $1(0.4)$ & $4(0.6)$ \\
Goiás & - & $7(2.3)$ & $1(0.4)$ & $8(1.2)$ \\
Maranhão & - & $3(1.0)$ & - & $3(0.5)$ \\
Minas Gerais & $6(8.1)$ & $65(21.0)$ & $59(25.0)$ & $130(21.0)$ \\
Mato Grosso do Sul & - & $1(0.3)$ & $1(0.4)$ & $2(0.3)$ \\
Pará & - & $1(0.3)$ & - & $1(0.2)$ \\
Paraíba & $14(18.9)$ & $40(13.0)$ & $24(10.2)$ & $78(12.6)$ \\
Pernambuco & $3(4.0)$ & $21(6.8)$ & $37(15.6)$ & $61(9.9)$ \\
Piaú́ & - & $7(2.3)$ & $2(0.8)$ & $9(1.5)$ \\
Paraná & - & $6(2.0)$ & - & $6(1.0)$ \\
Rio de Janeiro & $9(12.2)$ & $13(4.2)$ & $6(2.5)$ & $28(4.5)$ \\
Rio Grande do Norte & - & $5(1.6)$ & $1(0.4)$ & $6(1.0)$ \\
Rio Grande do Sul & $1(1.3)$ & $2(0.6)$ & $2(0.8)$ & $5(0.8)$ \\
Sergipe & & $4(1.3)$ & $4(1.6)$ & $8(1.2)$ \\
São Paulo & & $2(0.6)$ & $4(1.6)$ & $6(1.0)$ \\
\hline
\end{tabular}

(Table 3), while hypertension, dyslipidemia and diabetes mellitus were all more prevalent among elderly patients (Table 4).

LVEF was lower in patients with the cardiac form $(53.8 \pm 16.3 \%)$ than in patients with the indeterminate $(70.6 \pm 6.4 \%)$ or digestive $(68.1 \pm 8.0 \% ; F=88.7$, $P<0.0001)$ forms. There was a progressive worsening of the LVEF from stage B1 to stage D of the cardiac form (Table 5).

\section{Discussion}

Chagas disease is considered one of the neglected tropical diseases (NTD) which affect around 1.4 billion people, mainly in the poorest countries. The agenda of Sustainable Development Goals (SDG) for 2030 proposed by the United Nations recognize that eradicating poverty is the greatest global challenge and an indispensable requirement for sustainable development. The insertion of a specific goal (goal number 3) for the combat to NTDs in the SDG agenda is highly relevant as recognizes the link between poverty and NTDs and that the combat to poverty and NTDs must come together [19]. Our results are very important in combating $\mathrm{CD}$ when we localize the geographical origin of patients living in urban areas. It is possible that the integration of reference services for $\mathrm{CD}$ throughout Brazil will allow the investigation if relatives of our patients living in other states present $\mathrm{CD}$ infection. It is also possible that the identification of the areas where our young patients
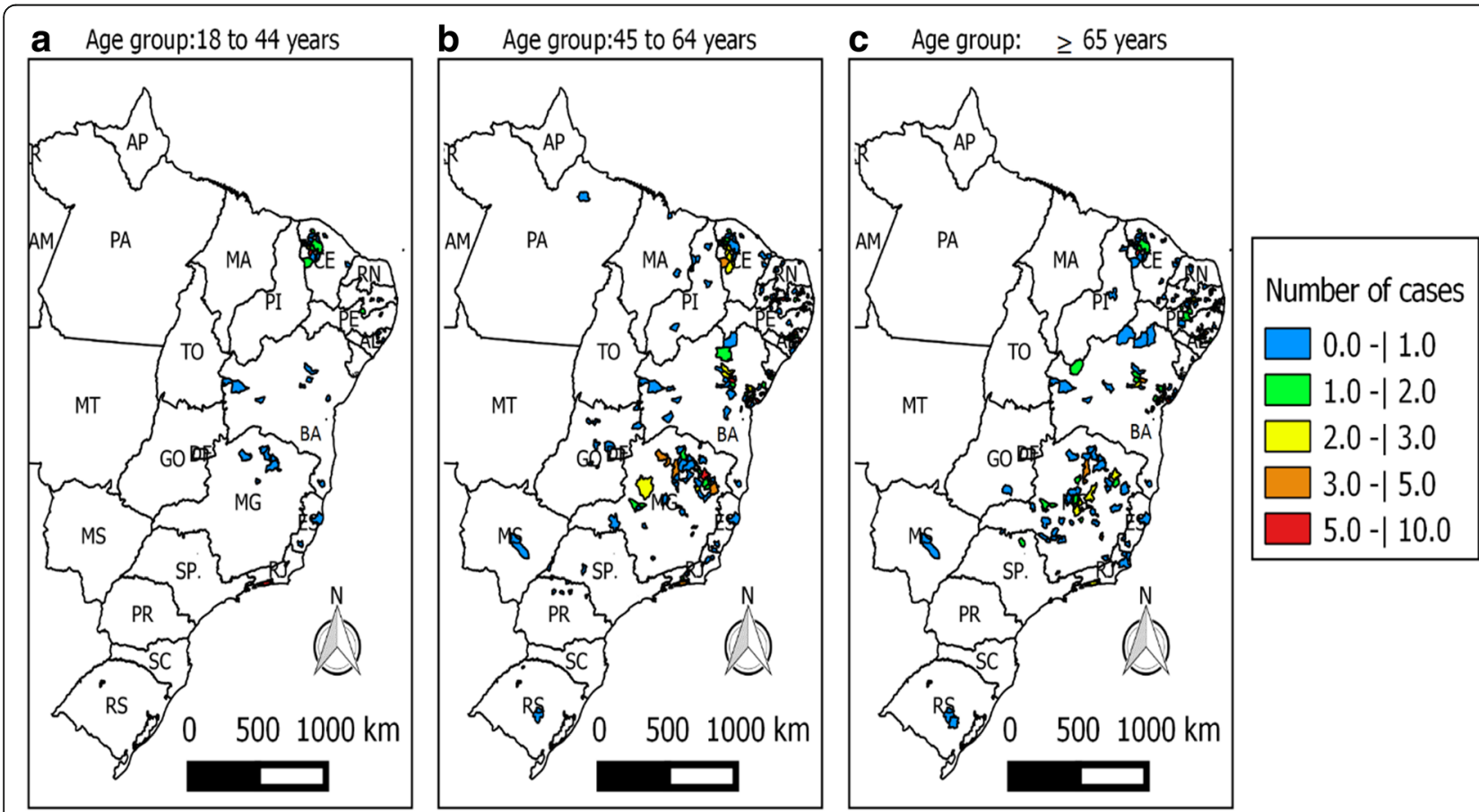

Fig. 2 Spatial distribution of INI cohort Chagas disease patients stratified by age group (a 18-44 years-old, b 45-64 years-old, c $\geq 65$ years-old) 
Table 3 Comorbidities frequencies according to Chagas disease clinical form

\begin{tabular}{lllll}
\hline Comorbidities & \multicolumn{4}{l}{ Clinical form $n(\%)$} \\
\cline { 2 - 5 } & $\begin{array}{l}\text { Indeterminate } \\
(n=180)\end{array}$ & $\begin{array}{l}\text { Cardiac } \\
(n=343)\end{array}$ & $\begin{array}{l}\text { Digestive } \\
(n=34)\end{array}$ & $\begin{array}{l}\text { Mixed } \\
(n=62)\end{array}$ \\
\hline SAH & $100(55.5)$ & $193(56.2)$ & $18(52.9)$ & $36(58.0)$ \\
Dyslipidemia & $84(46.6)$ & $137(39.9)$ & $12(35.2)$ & $28(45.1)$ \\
Diabetes mellitus & $53(29.4)$ & $112(32.6)$ & $5(14.7)$ & $15(24.1)$ \\
\hline
\end{tabular}

Abbreviation: SAH systemic arterial hypertension

were born will allow the investigation if those areas still present the conditions for active CD transmission.

The present study demonstrated a great proportion of elderly patients in the composition of an urban Brazilian $\mathrm{CD}$ patient cohort and a change in the most common place of birth among younger patients. Previous studies from our group described a mean age of the population followed at our outpatient service around $45.8 \pm 11.7$ years-old [20] . However, in the present study the mean age increased to 60 years-old in a period of 13 years. This finding is corroborated by others [21], which showed a progressive increase in the percentage of elderly patients enrolled in the Outpatient Unit of the Group for Studies into Chagas Disease at the Clinical Hospital of Campinas State University over 25 years (1980-2005). We also demonstrated a high frequency of comorbidities in our studied population with at least one comorbidity (hypertension, dyslipidemia or diabetes mellitus) present in $72 \%$ of the patients.

The increase in the proportion of elderly individuals among $\mathrm{CD}$ patients can be attributed to: a decrease in the $\mathrm{CD}$ incidence in Brazil due to the success of the vector and transfusion transmission control campaigns, improvement of the social status of the population with housing improvement in endemic regions, greater efficiency in diagnostic and therapeutic approaches [22, 23], and change in the Brazilian population general demographic profile with substantial aging of the population because of the fall in the rate of mortality associated with the rapid and marked decline of the fecundity rate. In fact, there is a progressive increase in the proportion of deaths among $\mathrm{CD}$ patients at a more advanced age, while the total number of deaths due to CD in Brazil is declining [24]. The increasing of migration and the progressive changes in rural economy modified the epidemiological patterns of the

Table 4 Comorbidities frequencies according to age groups

\begin{tabular}{lllll}
\hline Comorbidities & \multicolumn{2}{l}{ Age groups $n(\%)$} & P-value \\
\cline { 2 - 4 } & $\begin{array}{lllll}18-44 \\
(n=79)\end{array}$ & $\begin{array}{l}45-64 \\
(n=309)\end{array}$ & $\begin{array}{l}\geq 65 \\
(n=236)\end{array}$ & \\
\hline SAH & $6(7.6)$ & $178(57.6)$ & $163(69.1)$ & $<0.001$ \\
Dyslipidemia & $14(17.7)$ & $138(44.7)$ & $109(46.2)$ & $<0.001$ \\
Diabetes mellitus & $6(7.6)$ & $93(30.1)$ & $86(36.4)$ & $<0.001$ \\
\hline
\end{tabular}

Abbreviations: $S A H$ systemic arterial hypertension
Table 5 LVEF in patients with indeterminate and cardiac form of Chagas disease

\begin{tabular}{llllll}
\hline & Stage & $n$ & Mean & SD & $P$-value \\
\hline LVEF (\%) & Indeterminate & 164 & 70.6 & 6.4 & \\
& A & 112 & 69.2 & 7.5 & \\
B1 & 107 & 56.4 & $9.6^{*}+$ & $<0.001$ \\
B2 & 18 & 39.6 & $5.4^{*}$ 十キ & \\
C & 78 & 31.2 & $9.9^{*}$ 十キ & \\
D & 18 & 29.9 & $10.6^{*}$ 十キ\#\| & \\
\hline
\end{tabular}

ane-way ANOVA Bonferroni post-hoc

${ }^{*} P<0.05$ vs indeterminate; $+P<0.05$ vs stage $A ; \neq P<0.05$ vs stage $B 1$; $\# P<0.05$ vs stage $B 2 ; \| P<0.05$ vs stage $C$

disease, mainly in terms of its transmission and medical attention. Several areas have been modernized in terms of housing and production aspects with a radical change from the classical subsistence way of life to an agroindustrial and large-scale economy [12, 25].

The actions taken to control CD transmission in South America aimed at improving housing in endemic areas for $\mathrm{CD}$ and fulfilling the objectives of the Southern Cone Initiative [26] (of which Brazil is one the signatories), which consisted of eliminating $T$. infestans infestations from houses and peridomestic environments in endemic areas, reducing and eliminating the infestation of other triatomine species in the same areas occupied by $T$. infestans and reducing and eliminating the transmission by blood transfusions [26, 27]. Other factors also contributed to decrease the incidence of $\mathrm{CD}$ in Brazil, such as the urbanization process of the country with intense migration from rural to urban areas observed since the 1940s, and the increase in the income of the population [28].

The places of birth distribution of our cohort reflect traditional endemic areas [6]. As the route of transmission of more than $90 \%$ of our patients was vector-borne, we consider that the place of birth was the place where most patients were infected. Time living outside endemic areas is longer among patients with the cardiac and mixed forms than patients with the indeterminate form. This probably reflects longer time of disease among patients with determined forms of the disease than in patients whose disease had not yet progressed. However, the place of birth differs between older and younger patients probably due to different vector species present in the areas where younger patients were born. Therefore, the effectiveness of the vector control measures undertaken is probably different due to the different characteristics of the triatomines present in these areas. The main vector responsible for vectorial transmission in Bahia and Minas Gerais states was $T$. infestans, which was eradicated from domiciles, while $T$. infestans is not found in the State of Ceará where the main vector is the Triatoma brasiliensis. In the State of Paraíba, T. brasiliensis and Triatoma pseudomaculata are 
highly prevalent. Both species are native and present in the Caatinga ecoregion of both Ceará and Paraíba states [29, 30]. Triatoma pseudomaculata is considered a vector with an intermediate capacity to transmit $T$. cruzi while $T$. brasiliensis has a high effectiveness for $\mathrm{CD}$ transmission and is currently the most important vector in the Northeast Brazilian region $[29,30]$. These native triatomines need other control measures to avoid their role in the T. cruzi transmission. These control measures should focus on barriers to house infestation, such as indoor insecticide spraying and/or housing improvement interventions aimed at reducing the suitability of the domestic habitat [31-33]. The third state with more cases among younger individuals was Rio de Janeiro, the state where our institution is located. This can be explained mostly by vertical transmission and also by autochthonous transmission by $T$. vitticeps in specific Rio de Janeiro State rural areas [34]. An alternative explanation for the difference in place of birth present among different age groups would be a change in migration flow pattern from the Northeast Brazilian region to the State of Rio de Janeiro. In fact, during the 1970s and 1980s there was an intense flow from the Northeast region and State of Minas Gerais to the Southeast Brazilian region attracted by the economic development present in urban areas at that time, mainly in São Paulo and Rio de Janeiro states [10]. Nowadays, the economic development of the Northeast region associated to social policies contributes to a change in migration flow with a decrease in interstate migration flow and an increase in return migration. These dynamic changes in migration flow patterns may also contribute to the difference found in the place of birth composition between older and younger CD patients [35].

Our study and others $[36,37]$ have shown a higher proportion of women with $\mathrm{CD}$, although $T$. cruzi infection does not have a gender predilection [38]. This difference may be related to the more frequent use of health services by women, even after controlling for restrictions in routine activities due to health reasons [39]. The predominant clinical form of $\mathrm{CD}$ among patients included in this study was the cardiac form, followed by the indeterminate form, while digestive and mixed forms represented only $15 \%$ of the cohort. These findings are consistent with other studies in the literature, where the cardiac form is prevalent among elderly patients with CD $[16,40]$. However, asymptomatic patients may be unaware of their condition and may be not followed at health services. This would increase the proportion of patients with cardiac form in the cohort followed by health services.

Comorbidities frequency among elderly patients with $\mathrm{CD}$ in our study was high. The frequency of arterial hypertension among elderly patients with CD in our study was similar to others, however, diabetes mellitus and dyslipidemia frequencies in our study was higher than those described by others [40,41]. While we described diabetes mellitus and dyslipidemia frequencies of 36 and 46\%, respectively, others described diabetes mellitus frequency ranging between $10-14.4 \%$ [40, 41], and dyslipidemia frequency ranging between $20-31.9 \%$ [40, 41]. Arterial hypertension frequency among elderly patients with $\mathrm{CD}$ in our study was higher than in Brazilian elderly population. According to Andrade et al. [42], the frequency of hypertension in the general elderly population was $52.7-55.0 \%$ while in our study hypertension frequency was $69 \%$. Dyslipidemia and diabetes mellitus were also more frequent in our study than in the general Brazilian population. In the study of Iser et al. [43], the frequency of diabetes mellitus in general population was $19.9 \%$ and Bos et al. [44] reported dyslipidemia in $14.5 \%$ of the Brazilian general population. These differences may be accounted for the fact that people with comorbidities seek medical attention more frequently than people without comorbidities.

\section{Conclusions}

We described a great proportion of elderly patients in the composition of an urban Brazilian CD patient cohort and a change in the pattern of the place of origin among younger patients. We also demonstrated a high frequency of comorbidities in our studied population. In fact, the elderly patients with $C D$ comprise a group that has a high frequency of systemic arterial hypertension and other comorbidities (diabetes mellitus and dyslipidemia). Those are challenges to be overcome when developing new public health policies to address $\mathrm{CD}$.

\section{Additional file}

Additional file 1: Table S1. Dataset describing the raw data that support the conclusions of this article. (XLSX $55 \mathrm{~kb}$ )

\section{Abbreviations}

ANOVA: Analysis of variance; CD: Chagas disease; INI: Evandro Chagas National Institute of Infectious Disease; LVEF: Left ventricular ejection fraction; PAHO: Pan American Health Organization; SAH: Systemic arterial hypertension

\section{Funding}

This work was supported by Coordenação de Aperfeiçoamento de Pessoal de Nível Superior (CAPES/PROEX), Education Ministry, Brazil. The only role of the funding body was financial support for publication fees.

\section{Availability of data and materials}

The datasets supporting the conclusions of this article are included within the article and its additional file.

\section{Authors' contributions}

RMS and AGV conceived and designed the study. AGV, LHCS and AMHM collected the data. AGV, MCV, PEAAB and RMS contributed to statistical analysis. AGV, LHCS, AMHM, PEAAB and RMS contributed to interpretation and contextualization of the results and manuscript drafting. All authors have contributed for critical review, read and approved the final manuscript.

Ethics approval and consent to participate

This study was approved by the Research Ethics Committee of the INI under number 2303713.9.0000.5262. All procedures followed regulatory guidelines 
and standards for research involving human beings as stated in Brazilian National Health Council Resolution 466/2012 and were conducted according to the principles expressed in the Declaration of Helsinki in order to safeguard the rights and welfare of the participants. All patients gave informed written consent.

\section{Competing interests}

The authors declare that they have no competing interests.

\section{Publisher's Note}

Springer Nature remains neutral with regard to jurisdictional claims in published maps and institutional affiliations.

\section{Received: 15 January 2018 Accepted: 1 June 2018}

Published online: 19 June 2018

\section{References}

1. WHO. Chagas disease in Latin America: an epidemiological update based on 2010 estimates. Wkly Epidemiol Rec. 2015;90:33-44.

2. Pérez-Molina JA, Perez AM, Norman FF, Monge-Maillo B, López-Vélez R. Old and new challenges in Chagas disease. Lancet Infect Dis. 2015;15:1347-56.

3. World Health Organization. Working to overcome the global impact of neglected tropical diseases: first WHO report on neglected tropical diseases. Geneva: Department of Reproductive health and Research, World Health Organization; 2010

4. Schmunis GA, Yadon ZE. Chagas disease: A Latin American health problem becoming a world health problem. Acta Trop. 2010;115:14-21.

5. Martins-Melo FR, Ramos AN Jr, Alencar CH, Heukelbach J. Prevalence of Chagas disease in Brazil: a systematic review and meta-analysis. Acta Trop. 2014;130:167-74.

6. JCP D, Jr R, Novaes A, Gontijo ED, Luquetti A, Shikanai-Yasuda MA, et al. 2nd Brazilian consensus on Chagas disease. 2015. Rev Soc Bras Med Trop. 2016; 49:3-60.

7. Martins-Melo FR, Ramos AN, Alencar CH, Heukelbach J. Mortality from neglected tropical diseases in Brazil, 2000-2011. Bull World Health Organ. 2016:94:103-10.

8. Lee BY, Bacon KM, Bottazzi ME, Hotez PJ. Global economic burden of Chagas disease: a computational simulation model. Lancet Infect Dis. 2013;13:342-8.

9. Coura JR, Viñas PA. Chagas disease: a new worldwide challenge. Nature. 2010;465:S6-7.

10. Brito F. The displacement of the Brazilian population to the metropolitan areas. Estud Av. 2006;20:221-36

11. Moncayo A, Silveira AC. Current epidemiological trends for Chagas disease in Latin America and future challenges in epidemiology, surveillance and health policy. Mem Inst Oswaldo Cruz. 2009:104(Suppl. 1):17-30.

12. Coura JR, Dias JCP. Epidemiology, control and surveillance of Chagas disease: 100 years after its discovery. Mem Inst Oswaldo Cruz. 2009:104:31-40.

13. PAHO. XVa reunión de la Comisión Intergubernamental del Cono Sur para la eliminación de Triatoma infestans y la interrupción de la transmisión de tripanosomiasis transfusional (INCOSUR-Chagas). Washington: Communicable Diseases and Health Analysis, Neglected Infectious Diseases, Pan American Health Organization; 2006.

14. Shikanai-Yasuda MA, Carvalho NB. Oral transmission of Chagas disease. Clin Infect Dis. 2012:54:845-52.

15. ML e C, Barreto SM, Guerra HL, Firmo JOA, Uchoa E, Vidigal PG. Ageing with Trypanosoma cruzi infection in a community where the transmission has been interrupted: the Bambuí Health and Ageing Study (BHAS). Int Epidemiol. 2001;30:887-93.

16. Almeida EA de, Neto B, Madsen R, Guariento ME, Wanderley J da S, Souza $\mathrm{ML}$ de. Clinical presentation of chronic Chagas disease in elderly individuals. Rev Soc Bras Med Trop. 2007;40:311-315.

17. Lapa JS, Saraiva RM, Hasslocher-Moreno AM, Georg I, Souza AS, Xavier SS, et al. Dealing with initial inconclusive serological results for chronic Chagas disease in clinical practice. Eur J Clin Microbiol Infect Dis. 2012;31:965-74.

18. World Health Organization. World report on ageing and health. 2015. http://www. who.int/ageing/events/world-report-2015-launch/en/. Accessed 20 Apr 2018

19. United Nations. Transforming our world: the 2030 Agenda for Sustainable Development. 2015. https://sustainabledevelopment.un.org/post2015/ transformingourworld. Accessed 20 Apr 2018.

20. de Sousa AS, Xavier SS, de Freitas GR, Hasslocher-Moreno A. Prevention strategies of cardioembolic ischemic stroke in Chagas' disease. Arq Bras Cardiol. 2008;91:306-10.
21. Guariento ME, Carrijo CM, de Almeida E, Magna LA. Perfil clínico de idosos portadores de doença de Chagas atendidos em serviço de referência. Rev Bras Clin Med. 2011;9:20-4

22. Dias JCP, Silveira AC, Schofield CJ. The impact of Chagas disease control in Latin America: a review. Mem Inst Oswaldo Cruz. 2002;97:603-12.

23. Guariento ME, Alliegro FC, de Almeida E. Doença de Chagas associada a doenças crônicas em pacientes assistidos em ambulatório de hospital universitário. Rev Bras Clin Med. 2009;7:84-8.

24. da NAA, de AWN, Vasconcelos AMN. Mortality due to Chagas disease in Brazil according to a specific cause. Am J Trop Med Hyg. 2014;91:528-33.

25. Dias JCP. Globalization, inequity and Chagas disease. Cad Saúde Pública. 2007;23:S13-22

26. Schofield CJ, Dias JCP. The Southern Cone Initiative against Chagas disease. Adv Parasitol. 1999:42:1-27.

27. Dias JCP, Schofield CJ. Controle da transmissão transfusional da doença de Chagas na Iniciativa do Cone Sul. Rev Soc Bras Med Trop. 1998;31:373-83.

28. Coura JR, Borges-Pereira J. Chagas disease: 100 years after its discovery. A systemic review. Acta Trop. 2010;115:5-13.

29. Forattini OP. Biogeography, origin, and distribution of triatominae domiciliarity in Brazil. Rev Saúde Pública. 2006;40:964-98.

30. Sarquis O, Borges-Pereira J, Cord M, Roberto J, Gomes TF, Cabello PH, et al. Epidemiology of Chagas disease in Jaguaruana, Ceará, Brazil. I. Presence of triatomines and index of Trypanosoma cruzi infection in four localities of a rural area. Mem Inst Oswaldo Cruz. 2004:99:263-70.

31. Waleckx E, Gourbière $S$, Dumonteil E. Intrusive versus domiciliated triatomines and the challenge of adapting vector control practices against Chagas disease. Mem Inst Oswaldo Cruz. 2015;110:324-38.

32. Schofield CJ, Jannin J, Salvatella R. The future of Chagas disease control. Trends Parasitol. 2006;22:583-8.

33. Dias JCP. Evolution of Chagas disease screening programs and control programs: historical perspective. Glob Heart. 2015;10:193-202.

34. Sangenis L, Saraiva R, Georg I, de Castro L, dos Santos Lima V, Roque A, et al. Autochthonous transmission of Chagas disease in Rio de Janeiro State, Brazil: a clinical and eco-epidemiological study. BMC Infect Dis. 2015;15:4.

35. Lima ACC, Simões R, Hermeto AM. Desenvolvimento regional, hierarquia urbana e condição de migração individual no Brasil entre 1980 e 2010. EURE Santiago. 2016:42:29-54.

36. Matos CS, dos Santos JE, Medeiros FAC, Furtado E, Dias JCP. Current situation and perspectives regarding human Chagas disease in midwestern of the state of Minas Gerais, Brazil. Mem Inst Oswaldo Cruz. 2014;109:374-8.

37. Marcolino MS, Palhares DM, Ferreira LR, Ribeiro AL. Electrocardiogram and Chagas disease: a large population database of primary care patients. Glob Heart. 2015;10:167-72.

38. Kirchhoff LV. Chagas disease (American trypanosomiasis): background, pathophysiology, epidemiology.2016. http://emedicine.medscape.com/ article/214581-overview\#a6. Accessed 15 Nov 2016.

39. Travassos C, Viacava F, Pinheiro R, Brito A. Utilização dos serviços de saúde no Brasil: gênero, características familiares e condição social. Rev Panam Salud Pública. 2002;11:365-73.

40. de Alves RM A, Thomaz RP, de Almeida EA, da Wanderley J S, Guariento ME. Chagas' disease and ageing: the coexistence of other chronic diseases with Chagas' disease in elderly patients. Rev Soc Bras Med Trop. 2009;42:622-8.

41. Pereira $L$ dos $S$, Freitas EC, Fidalgo ASO de BV, Andrade MC, Cândido D da S, da Silva JD, et al. Clinical and epidemiological profile of elderly patients with Chagas disease followed between 2005-2013 by pharmaceutical care in Ceará State, northeastern Brazil. Rev Inst Med Trop São Paulo. 2015;57: 145-52.

42. de Andrade SS A, Stopa SR, Brito AS, Chueri PS, Szwarcwald CL, Malta DC. Prevalência de hipertensão arterial autorreferida na população brasileira: análise da Pesquisa Nacional de Saúde, 2013. Epidemiol E Serviços Saúde. 2015;24:297-304.

43. Iser BPM, Stopa SR, Chueiri PS, Szwarcwald CL, Malta DC, da Monteiro HO C, et al. Prevalência de diabetes autorreferido no Brasil: resultados da Pesquisa Nacional de Saúde 2013. Epidemiol E Serviços Saúde. 2015;24:305-14.

44. Bos AJG, Jorge LB, do Navarro JH N, Gerlack LF, de Rocha J P, Oliveira GG, et al. Comparing the prevalence and drug treatment rates of diabetes, hypertension and dyslipidemia between Japan and Brazil, using 2013 National Health Surveys. J Clin Diabetes Pract. 2015;1:103. 